\title{
MODELLING CONTEXT: A CASE OF DALANG TRAINING
}

\author{
(Modelando contextos: um caso de formação Dalang)
}

\author{
Albert Tallapessy ${ }^{1}$ \\ (Macquarie University - Sydney)
}

\begin{abstract}
This paper discusses pedagogic discourse in dalang (shadow play puppeteer) training. Systemic Functional Linguistics will be used as a tool for analysis. The concept of metafunctions will be employed to view realisations from each level of abstraction. Modelling, which is a critical issue in pedagogic discourse will be explored to know how a teacher uses "critical abstraction" - semiotic guidance in developing a skill. Classification and framing and notion of zone of proximal development will also be discussed on the discourse production.
\end{abstract}

Key-words: metafunction, classification, framing, zone of proximal development

\section{RESUMO}

Este artigo discute o discurso pedagógico em formação Dalang (titereiro de teatro sombra). Princípios da Lingüística Sistêmico Funcional serão utilizados como uma ferramenta para análise. O conceito de metafunções será empregado para ver as realizações de cada nível de abstração. Modelagem, que é uma questão crítica no discurso pedagógico, será explorada para saber como um professor usa "abstração crítica" - a orientação semiótica para desenvolver uma habilidade. Classificação,

1. The author is a lecturer at the English Department, the Faculty of Letters, Jember University, Indonesia. Currently he is a $\mathrm{PhD}$ student at the Linguistics Department, the Faculty of Human Sciences, Macquarie University, SydneyAustralia. His research interest is on stylistics. His PhD project is on Javanese Shadow Play. He uses Systemic Functional Linguistics (SFL) as a tool to explore how this tradition is transferred from the guru (teacher) to the student. 
enquadramento e noção de zona de desenvolvimento proximal também serão discutidos sobre a produção do discurso.

Palavras-chave: metafunção, classificação, enquadramento, zona de desenvolvimento proximal

\section{Introduction}

This paper discusses the dalang (puppeteer) training as a special process. To give a close picture of the transferring of knowledge, context network will be introduced. Bernstein's theory (e.g. 1975, 1990, 2000) of pedagogic discourse will also be argued in order to give notion on pedagogic device, especially on the use of language which is called decontextualisation (Cloran, 1999). The concept of modelling (Butt, 2000) which leads to the use of abstract tools will be deployed to know the teacher strategy in exploring the meaning.

This project is an exemplum of how highly valued dalang techniques are sustained (and adapted) from the master to apprentices. Systemic functional linguistics (SFL) is used as tool for analysis. SFL's conception of metafunctions will be deployed to view the notion of realisation from context to semantics and from semantics to lexicogrammar. Vygotsky's notion of zone of proximal development (ZPD) will be used to analyse how a teacher widens this notion by using linguistic choices in the process of scaffolding.

\section{The Dalang (puppeteer)}

A Dalang is a person who performs shadow play. In any shadow play performance the dalang plays many functions, which is in other art forms will be the work of separate individuals. He is a playwright, a director and an actor (van Ness, et al, 1980: 43). The dalang's profession is based on a centuries-old tradition that has been orally transmitted, mostly from father to son (Groenendael, 1985: 2). A Dalang should master 5 basic skills: sastra (literature), catur (language), gendhing (music), sabet (movement), suluk (mood song). Besides, he should 
also master certain amount of esoteric knowledge. This knowledge includes special spell and incantations (mantra) and certain code of behaviour which enable him to have power to overcome such problems as droughts, plague affecting the crops, individual fortune and his own success as dalang (Groenendael, 1985).

\section{Shadow Play}

Shadow play is a Javanese traditional play which uses puppets as characters. It is performed on a white clothe screen functions as a stage for a dalang to present his performances. The puppets are sticked on two banana trunks, arranged neatly on the right and left hand side of the screen. Above, on the middle of the screen, a lamp is hung to project shadow on the screen. During a nine-hour performance, a dalang sits cross legs, singing, narrating the story, creating dialogues and moving the puppets with his dynamic movement. In the centre of the stage he is the axis of the space of the stage.

On the right hand side of the dalang five to seven, sometimes more, female singers (pesinden) sit in one line, singing Javanese songs during the performance. Thirty to forty musicians (niyaga) sit behind the dalang, playing the orchestra of the shadow play. Led by a drummer (pengendang) the musicians play various kinds of Javanese classical music from slow to dynamic beats. They accompany the dalang creates the dramatic situation of the play.

\section{Systemic Functional Linguistics (SFL)}

SFL has been developed since 1960s by M.A.K Halliday developing the work of Saussure, Malinowski, and Firth. The latest edition of Halliday's systemic functional description of the grammar of English was published in the third edition of an Introduction to Functional Grammar. Later, this grammar was also used to describe other languages e.g German, French, Chinese, Vietnamese and many others (Caffarel, Martin, and Matthiessen, 2004). 
The SFL approach has been a powerful tool to analyse language as a meaning making system. Since it was introduced this theory has been applied to many sub-disciplines of linguistic research. SFL is applied on theoretical, historical, and development concerns. In recent years this theory has been applied in the field of language of education, the semiotic of visual art, artificial intelligence and speech pathology (Eggins, 1994). Moreover in this multimodal era SFL becomes the powerful tool to analyse multimodal discourse analysis (MDA). SF theory is well placed to provide theoretical tools for any discourse analysis because it is a social semiotic theory where the meaning is seen to be context-dependent (Halliday, 1978). It is from the very beginning that SFL connects its analysis to the cultural and social context in which the language is embedded. Context becomes keyword in analysing the text because it is the environment which accompanies the text (e.g Halliday, 1999: 3; Hasan, 1985).

\subsection{Register}

Register is a semantic concept which can be defined as configuration of meaning in a particular situational configuration of field, tenor and mode (Halliday, 1985: 38). Field refers to the institutional setting in which a piece of language occurs; tenor refers to the relationship between participants; and mode refers to the channel of communication adopted (1978: 33). According to Halliday field is the type of social action, tenor is the role relationship and mode is the symbolic organisation (1978: 35). At later development the three concepts are related respectively to the ideational, interpersonal and textual components of the semantic system (1978: 125).

In Halliday's view, 'the notion of register is at once very simple and very powerful' and provides a means of investigating the linguistics foundation of everyday social interaction from an angel that is complementary to the ethno methodological one'; it takes account of the processes which link the features of the text, considered as the realisation of semantic patterns, to the abstract categories of the speech 
function (1978: 31, 62). Theory of register attempts to uncover the general principles which govern the the language that we speak or write varies according to the type of situation (1978: 32).

Matthiessen argues that that register shows one fundamental element of the organization of langue in context. To explore register and register variation we need to look at the dimensions of this in overall organisation. The language in context is organised globally along the dimensions of stratification (orders of symbolic abstraction related by realization), metafunctional diversification (modes of meaning), and potentiality (the dimension from potential to instantial through instantiation - from system to text (1993: 225).

The term 'genre' is often interchangeably with the word register, although in genre theory register is considered the expression plane of genre (e.g. Eggins and Martin, 1997; Martin, 1997). Genre is seen as "staged, goal-oriented social process" (Martin and Rose, 2007: 8), while register is the configuration of the contextual variables of field, tenor and mode (Martin and Rose, 2007: 297).

\subsection{Instantiation}

SFL views that "the grammar of a language is represented in the form of system networks, not an inventory of structures "(Halliday and Matthiessen, 2004: 23). In SFL, "a language is a resource for making meaning, and meaning resides in systemic pattern of choice" (Halliday and Matthiessen, 2004: 23). Thus language can be analysed in two perspectives: as a text (instance) and as a system (potential) (Halliday and Matthiessen, 2004: 19). These create two poles on 'a cline of instantiation', where each text 'initiates' the potential. "System and text are not different phenomena; they are only different 'phase' of one and the same phenomenon" (Matthiessen, 2002: 242). From this point of cline of instantiation, Halliday and Matthiessen (2004) call as register.

Therefore, register is seen as a setting of semantic probabilities (Halliday and Matthiessen, 2004; Matthiessen, 1993). Register does not only instantiate the potential of context of situation but also an 
instantiation of the total meaning potential, a linguistic realisation of the potential variation in contexts of situation. Halliday and Matthiessen (2004: 21) demonstrated that all strata are operational at each point on the cline of instantiation.

\subsection{Stratification}

SFL views language through the notion of stratification. Language can be models at a number of different levels of abstraction. Halliday and Hasan (1985) modelled this stratification into four layers "which are both necessary and sufficient for a satisfactory description of language "(Hasan, 1999: 224). Deriving from Saussure's (twosided) conceptualisation of the sign, the stratification is divided into content and expression planes, where the content (semantic and lexicogrammar) is realised by the expression (phonology or graphology, as realised by phonetics) (Halliday and Matthiessen, 2004: 24-25; Hasan, 1999: 224). The higher level of abstraction, external to language, is the context stratum. Semantics and phonology are viewed as 'interlevel' mediating between context and lexicogrammar, and lexicogrammar and phonetics (Teich, 1999: 13).

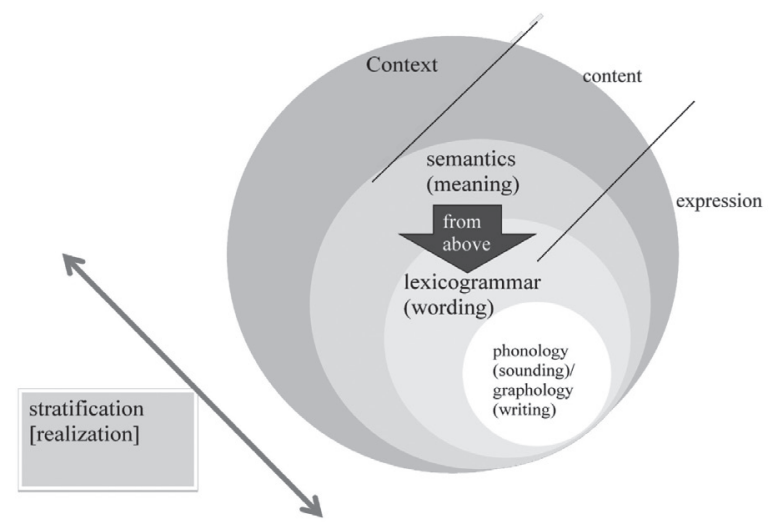

Figure 1. Stratificational model of language and context 
It is from the early stages that SFL theory agrees on the importance of invoking the contextual stratum when investigating the use of language in social life (Ventola, 1987: 21). Thus, the notion of stratification is central to the context based approach of SFL. Furthermore, this model of stratification is also used in other related SFL model. For example, following Hjelmslev (see e.g Halliday and Martin, 1993; Martin and Rose, 2007: 3008-309; Ventola, 1987: 57 62) the stratification is identified as the 'communicative planes' of the connotative semiotics framework. In this framework, register, genre and ideology are modelled as semiotic systems operating as content plane of language (Martin and Rose, 2007: 308). They are semiotic systems operating as communicative planes in which the lower strata are their expression plane (Butt, 2001: 1831). Therefore, register is "the expression form of genre, at the same time as language functions as the expression of register" (Martin, 1992: 495).

\subsection{Context}

Halliday (1999: 3) defines context as something that accompanies the text. In the stratal model of language it is located at the 'extralinguistic' layers, outside language property. It is related to language, as it is realised by semantics. Context includes both context of situation and context of culture (e.g Halliday and Hasan, 1985: Hasan 1999). While context of situation refers to the immediate relevant social context of the linguistic interaction (Hasan, 1999: 232), context of culture refers to the social system, "a set of semiotic systems, a set of system of meaning, all of which interrelate" (Halliday and Hasan, 1985: 4). Hasan further explains that context of culture is instantiated by the context of situation (Hasan, 1999: 224). The relation of language to culture is "a theoretical issue most fundamental to linguistic theory but "remains in need of elaboration" (Hasan, 1999:220).

Context of situation is modelled by using three parameters: field, tenor and Mode. Halliday (1999) explains these three parameters as follows: 
The field of discourse refers to what is happening, to the nature of the social action that is taking place: what is it that participants are engaged in, in which the language figures as some essential components?

The tenor of discourse refers to who is taking part, to the nature of the participants, their status and roles: what kinds of role relationship obtain among the participants, including permanent and temporary relationships of the one kind or another, both the types of speech role that are taking on the dialogue and the whole cluster of socially significant relationship in which they are involved?

The mode of discourse refers to what part of language is playing, what it is the participants are expecting the language to do for them in that situation: the symbolic organisation of the text, the status that it has, and its function in the context, including the channel (is it spoken or written or some combination of the two?) and also the rhetorical mode, what is being achieved by the text in terms of such categories as persuasive, didactic, and the like (Halliday and Hasan, 1985:12).

\subsection{Metafunction}

The SFL models meaning into metafunctions. At the semantics stratum, the meaning is classified into ideational, interpersonal and textual metafunctions. The ideational metafunction, comprising experiential and logical components, is concerned with construing experience -it is language as theory of reality, as a resource of reflecting the world (Halliday and Matthiessen, 1999: 7). While interpersonal metafunction is concerned with enacting interpersonal relation through language, textual metafunction is concerned with organising ideational and interpersonal meaning as discourse (Halliday and Matthiessen, 1999: 7-8). At the level of context, these metafunctions refer to the three context parameters: field, tenor and mode. Field refers to the institutional setting in which a piece of language occurs, tenors refers to the relationship between participants, and mode refers to the channel of communication (Halliday, 1978: 33). The overlap system about these metafunction is presented in the following diagram. 


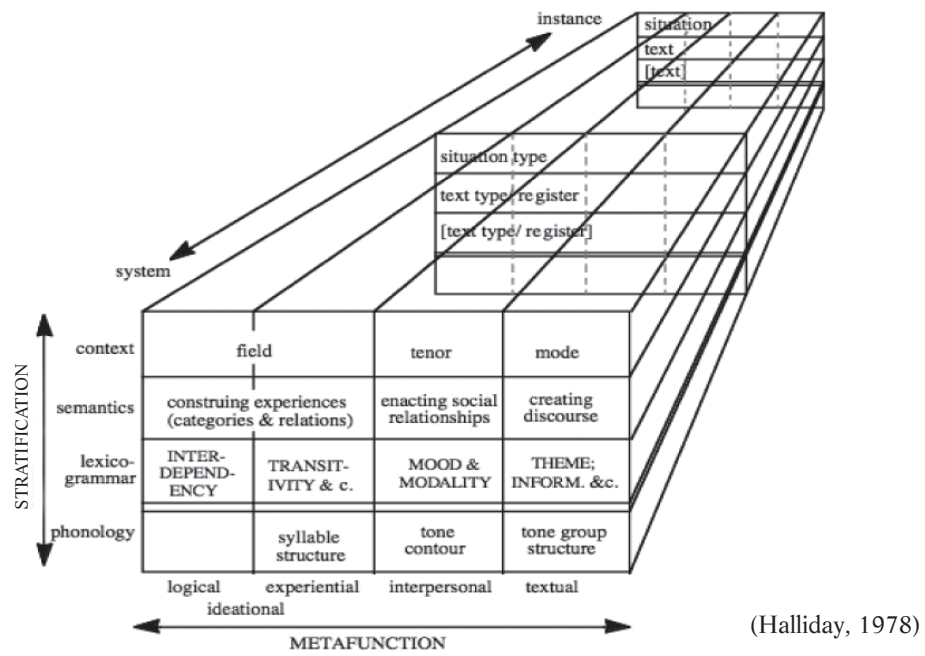

Figure 2. Dimensions of Language addressed in the SFL model

\section{Pedagogic Discourse}

Pedagogic discourse is any discourse connected with any aspect of educational practices (Hasan, 2005: 29). It embeds a discourse of competence into a discourse of social order in such a way that the latter always dominates the former (Bernstein, 1990: 183). This conception is represented as Instructional Discourse (ID) and Regulative Discourse (RD).

I will define pedagogic discourse as a rule which embeds two discourse; a discourse of skills of various kinds and their relation to each other, and a discourse of social order...the instructional discourse is embedded in the regulative discourse...to create one text...one discourse...the regulative discourse is the dominant discourse...produces the order in the instructional discourse...the purposes of the device is to produce a symbolic rules for consciousness (Bernstein, 1996: 46-50 cited in Martin, 1999: 142). 
From the perspective of functional linguistics Martin tends to use the projection rather than embedding. Thus, the regulative discourse projects the instructional one (1999: 143). Martin further explains that literacy pedagogy could be enhanced by adding a second instructional discourse derived from social semiotic theory, and using it to project interactional discourse (1999: 143). In a simpler term, it is a way to introduce explicit knowledge about text in social context that could be deployed through the pedagogic cycle. For example, Veel (1997) uses explicit understanding when he worked on scientific knowledge. Martin outlined this concept in the following figure.

\begin{tabular}{|ll|}
\hline ID & instructional discourse \\
SSID & social semiotic instructional discourse \\
RD & regulative discourse \\
\hline
\end{tabular}

\begin{tabular}{|c|c|c|}
\hline & ID & IS \\
\hline ID & SSD & $\mathrm{RD}$ \\
\hline $\mathrm{RD}$ & $\mathrm{RD}$ & SSID \\
\hline
\end{tabular}

(Martin, 1999: 144).

A critical concept in this sociology of pedagogy is pedagogic device (Bernstein, 2000). This refers to the whole potential of pedagogic discourse. All forms of pedagogic communication are instantiations of the pedagogic device, which consists of three interrelated sets of rules: (1) distributive rules which distribute forms of consciousness through the distribution of forms and knowledge, (2) recontextualising rules which regulates the formation of specific instructional discourse, and (3) evaluative rules which furnish criteria for legitimate forms of communication (Hasan, 2005: 29). Furthermore, she claims that pedagogic discourse is always and unavoidably hierarchic, in which the hierarchic position between the "transmitter" and the "acquirer" might or might not be visible. This leads to the distinction between 
"visible" and "invisible" pedagogy (Hasan, 2005: 29). Framing and classification will characterise both visible and invisible pedagogy. The choice of them is a communication strategy built by a transmitter i.e the teacher.

A characteristic feature of pedagogic discourse according to Bernstein's view is the use of decontextualised language (Cloran, 1999: 32). It is a language which is context independent (Bernstein, 1971). In the decontextualisation's process the meaning of signs become less dependent on the unique-temporal context in which they are used (Wertsch, 1985: 33).

\subsection{Reframing Pedagogy}

The development of pedagogy in teaching literacy is much influenced by Vygotsky His notion of zone of proximal development (ZPD) contributes on significance approaches on the teaching, especially on the issue of scaffolding.

The zone of proximal development (ZPD) is the distance between the actual development level as determined by independent problem solving and the level of potential development as determined through problem solving under adult guidance or in collaboration with more capable peers. (Vygotsky,1978: 86)

The notion of guidance through interaction in the context of shared experience has remained fundamental (Martin, 1999: 126). This guidance through interaction leads the rise of teaching model, which has been realised in what Christie (1999) calls curriculum genre. Instructing, modelling, questioning and cognitive structuring are among the linguistic devices used in the guidance model (Tharp and Gallimore, 1999).

Modelling is crucial on this study because through this way a teacher explains a concept to his students. At the case of shadow play, for example, a teacher needs to model his explanation by using kinesic or verbal modelling. Kinesic is used to model movement in order that 
students can imitate the teacher's examples, while verbal modelling is used to explain difficult concept, something that Butt (2000) calls as critical abstraction (CA). The status of critical abstraction in relation to specialised language, or register can be set out in the following way (Butt, 2000: 8):

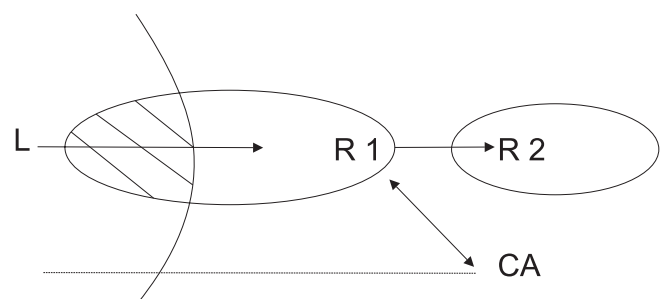

Figure 3. Critical Abstraction

The general based meanings of a language (L) are to meet the demand of a new context which needs meanings beyond the range and usage in the community (R1). However, certain terms and pattern of the language (L) are used in the evolving register (R1). Critical abstraction (CA) is the rhetorical strategy that is introduced in order to clarify a variety of meaning (R1, R2, etc) for those who experience the semantic opacity of the outsider (Butt, 2000: 9). The critical abstraction transforms the talk around and the ability by revealing the semiotic basis for the way the activity is represented: when one reads a map, for example, one needs to know that the projections are sound for the shape of a country, but wrong about the relative size of one countries. One needs to understand how the representation in CA makes this clear.

\subsection{Context of the dalang training}

To give a general picture of the dalang training I will characterise the contexts in which they occur in term of field, tenor and mode (Butt, 2003: Halliday, 1978; Halliday and Hasan, 1995; 1999; Martin 1992). 


\begin{tabular}{lll}
\hline Field & Social process & teaching and learning \\
\hline & domain : & $\begin{array}{l}\text { dalang techniques: sastra (literature), } \\
\text { sabet (movement), suluk (mood song) } \\
\end{array}$ \\
& music (music), catur (language) \\
\hline Tenor & institutional role: & teacher to student \\
& hierarchy : & teacher-student interaction \\
& distance: & interactants know each other \\
& speech role: & transferring dalang techniques \\
\hline Mode & medium: & spoken \\
& channel: & direct conversation, dialogic \\
\hline
\end{tabular}

Table 1: The context of dalang training

\section{Context Network: initial analysis}

There are two teachers compared to find how the network system operates on each group. The first is network among a teacher (teacher 1) and his students in a dalang school located at Trenggalek, a town in East Java, Indonesia. The second is the interaction among the other teacher (teacher 2) with his three students in another dalang school at Java. Teacher 1 is a teacher at the Pedalangan Department, Indonesia Art Institute. Based on request of a dalang school he teaches this group once a month. The students of this dalang school are professional dalangs who need to improve their dalang skills. Most of them are older than the teacher. This makes the teacher delivers his teaching by using high level of Javanese, the language which is commonly used to show the distance and power among the participants

Teacher 2 is a professional dalang. His schedule for performance is very tight. In a month he performs 15 shadow play performances average. On his tight schedule he also thinks about having students. The students discussed here are three of his seven students. These three students have known the teacher for a long time. Two of them shared the same high school, although at different levels. Before learning to be dalangs, they have worked for the teacher for a number of years. Their duties were to prepare equipment for the shadow play performance. Later, two of them became the teacher's musicians and the other one became a singer (niyaga). 
While I cannot show the context networks I draw for the project in this article (See Butt, 2003; Butt, 2004 elaborating and modifying Hasan, 1999, for a fuller explanation), on the following sections I will present the summary of the networks.

\subsection{Field}

Field refers to what is going on in the situation of the dalang training. There are four systems: SPHERE OF ACTION, MATERIAL ACTION, ACTION WITH SYMBOLS, and GOAL ORIENTATION. In relation to SPHERE OF ACTION, the training is 'specialised: irrealis: heuristic: imaginary: fictive.' In other words, this training is not a kind of routine. It is a special event where the process involves the expert and the students (apprentices).

While The MATERIAL ACTION is obligatory, the ACTION WITH SYMBOLS deals with the systems of 'necessary: guiding: instruct: create: resource: refashion'. The selections from the system of GOAL ORIENTATION are 'longitudinal: defined by activity: from outset: vanable: integrated.'

\section{2 Tenor}

The tenor network deals with SOCIAL HIERARCHY, AGENTIVE ROLE, SOCIAL DISTANCE and NETWORK MORPHOLOGY. In terms of SOCIAL HIERARCHY the networks are 'hierarchic: advisory: by Expertise,' 'deferred to', 'repercussive: status. For the following choices there are differences between teacher 1 and teacher 2 . Teacher 1 is 'undeclared' and 'immutable,' while the options for teacher 2 are 'declared,' 'mutable: role changes.'

AGENTIVE ROLE is the next choice on this tenor network. Both teachers share the same choices. The systems are 'acquired,' 'civic: by status: expertise,' and reciprocating.' Acquired because this dalang expertise is got from the training. Civic because the actant is based on civic determinations. It is 'by Status' since the civic determinations function on the dalang status. Dalang profession is an expertise that 
is why 'expertise' is the next choice. Finally 'reciprocating' is chosen on the AGENTIVE ROLE because of the two way direction of the participant in the context, the dalang and the students.

The SOCIAL DISTANCE network of the first teacher and his students are 'uniplex: business: assigned.' They are followed by regular: recurrent.' Both the teacher and the students come to the school through one link: Mr Sunarto's (the head of the school) invitation. It is the reason for choosing 'uniplex' on this network. This link is based on their business as artists. In other words it is assigned on their work. Thus the network comes after 'uniplex' is 'business and assigned.' The following is regular since contact is required to maintain the social distance between the participants. The school's meeting is once a week (regular), thus it is 'recurrent.' Different from the first teacher, the second teacher's network in terms of SOCIAL DISTANCE is 'multiplex: personal: outer: neighbourhood,' 'vocational: community role'. The teacher knows his students from many channels: school, neighbourhood, and workplace.

The next issue should be chosen on the systems are Codal Sharing. Both the two teachers share the same choices on this network. The choices are 'local history in common: neighbourhood: 0,0 , and 0 . They are followed by 'extended' (over time), 'training in common: multiple: school', 'business in common: workplace,' 'recreation in common: participant: doer.'

This dalang school has a regular meeting, thus, it is 'institutionalized.' This is the reason for choosing training in common for the following network. This option is followed by multiple, school, 0 and professional. The training is formulated in the dalang school. It is professional, but it is not tertiary education. The network, then, expands to business in common, workplace, recreation in common and doer.

Referring to Cultural Capital in Common, the network systems are techniques/ skill, 0, aesthetic, 'public visibility high: celebrated, and unidimentional (STOP). Dalang is a profession that needs training to meet the skill. It is not inherited. Despite the fact that there are many professional dalangs who come from the dalang families, they need training. It is aesthetic because shadow play is an art form. Both teachers 
have the same choices in this network. The last system belongs to tenor network is NETWORK MORPHOLOGY. In this system the teachers' choices are also the same. They are 'non scale: group: cross related,' then field-dependent role. The Scalar includes 'density: high,' 'diversity: high,' 'direction: both ways,' 'centrality: high,' and 'clustering: high.'

\subsection{Mode}

Mode deals with the semiotic role that language is playing in the unfolding context: the division of labour between language and other semiotic processes, or social processes, in creating situation, the channel assigned to language (Metthiessen, et al, 2005: 129). Here the systems are ROLE OF LANGUAGE, CHANNEL, and MEDIUM. The role of language is 'constitutive: abstracted: heuristics: pedagogical: modelling.' The CHANNEL is 'phonic: human: linguistic,' 'real time: face to face,' 'multiple: overlaid.' The MEDIUM is 'spoken like' and 'choreographic-movement' and 'wave: phased intricacy.' The field tenor and mode values together form and constrain an organisation of sequence that creates generic structure. The generic structure of the dalang training is set out in the following table.

\section{Generic Structure}

Pedagogical

Orientation

Play the first scene. The story is Narayana Begal

\begin{tabular}{ll}
\hline Student Response & $\begin{array}{l}\text { (the student presents the task) } \\
\text { Initial Intervention }\end{array}$ \\
\hline $\begin{array}{l}\text { You didn't move your puppet, the spectator may get bored. } \\
\text { Do like this. }\end{array}$ \\
\hline Intervention & Too quick. Stop. Sop. Stop in the middle (of the screen). \\
\hline Student Rephrase & (the student represent the task) \\
\hline Intervention & $\begin{array}{l}\text { Correction: } \\
\text { Your dodog first and then narrate. Udawa should put his hand } \\
\text { on waist. }\end{array}$ \\
\hline $\begin{array}{l}\text { Pedagogical } \\
\text { Submission }\end{array}$ & $\begin{array}{l}\text { Most of your performances are correct. But if you want to } \\
\text { change the puppet, for example Udawa, the important thing is } \\
\text { characterisation. So you must show how happy Udawa was af- } \\
\text { ter he got a supernatural power. You must show your happiness. }\end{array}$ \\
\hline
\end{tabular}

Tabel 2. Generic Structure of the dalang training 


\section{Stratification: semantic and lexicogrammar}

In this section I will discuss the teaching process by using multistratal analysis focusing on semantics and lexicogrammar. On the first part I will discuss the discourse that a teacher (teacher 1) produces when he makes comment after a student presents his performance (Pedagogical Submission).

$\begin{array}{lll}\text { T1 } & 12 & \text { At the beginning Mr. Lurah knocked at the box. } \\ 13 & \text { Dodok is a request } \\ 14 & \text { The request depends on the person who requests } \\ 15 & \text { If the dodok is too slow } \\ 16 & \text { the music will slow too } \\ 17 & \text { So, make the dodok quicker } \\ 18 & \text { You knocked the dodok too slowly } \\ 19 & \text { Too long } \\ 20 & \text { Like this (the teacher gives an example) }\end{array}$

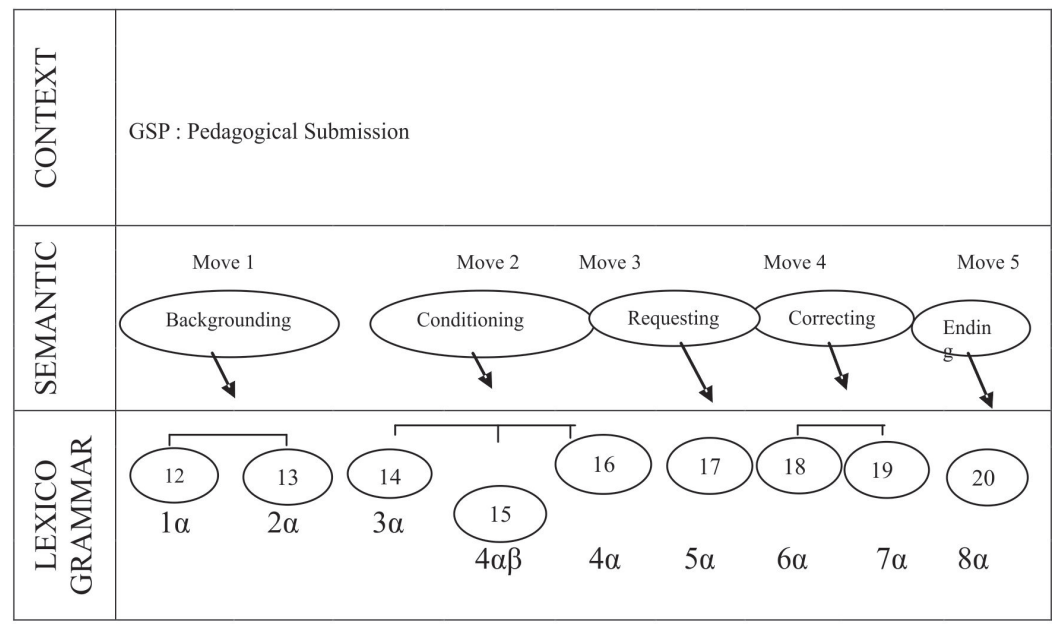

Figure 4. Multi-stratal Analysis: teacher 1

This extract shows how the teacher models his correction to his student's mistake. The mistake that the student make is that he knocks the dodok (a wooden equipment) too slowly. This makes the tempo of the music slowl too. The main problem that the teacher wants to correct is clause 18 and 19 . However, he does not directly say that the way that the students knock the box (dodok) is too slow. He starts from backgrounding (clause 12 and 13). This backgrounding 
is an introduction to the problem. In clauses 14 to 16 the teacher methodologically gives the analogy by using conditional sentence. While clause 17 is his request to correct his mistake, clause 18 is the main problem of the student's performance. He ends his session with the ending in clause 20.

What the teacher uses in modelling the explanation is critical abstraction. He models the explanation by using analogy. At the level of semantic there are five moves which are realised from the context at the higher level. At the level of lexicogrammar, as realisation of semantic, there are 9 clauses in parataxis and hypotaxis relation. The mood choices are declarative and imperative.

The teacher carefulness in modelling his explanation means that he uses strong framing and strong classification. On this phase it is common that a teacher using strong framing and strong classification because the field of the discourse is already open. He wants to make sure that the student is able to perform the technique well. In other words he tries to open the student's ZPD.

Now, I will compare the teacher above with another teacher (teacher 2) on another dalang school. It is a session where the teacher stops the student's presentation because of mistakes he has made (Intervension).

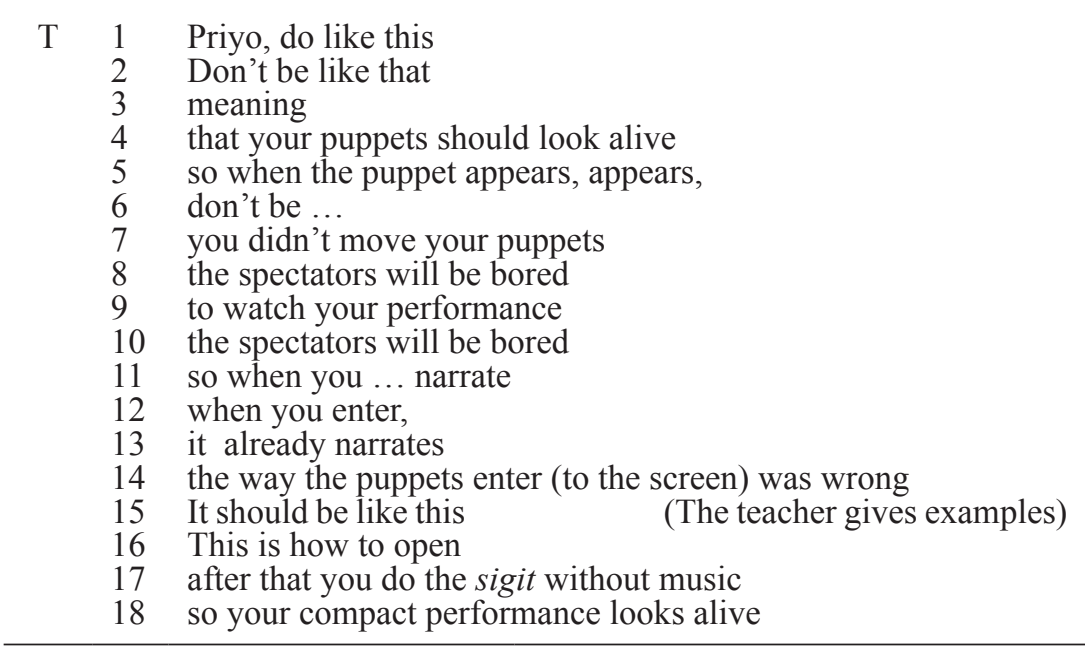


The context of the teaching is how to make the dolls look alive. It is part of movement techniques in shadow play. The teacher makes correction by using imperative mood (clause 1 and 2). He wants to argue that his student's performance is not alive. At the semantic level he is directing to make the puppets alive. He makes equation $\mathrm{X}=\mathrm{Y}$. While X refers to clause 1 and clause 2 and Y refers to clause 4. Clauses 7 to 14 are the problem statements. These consist of a list of problems that make the student's puppets are not alive. Clauses 15-17, on the other hand, are the teacher's correction. He uses verbal modelling and kinesic to explain this section. Clause 18 strengthens the teacher's argument about the importance making the puppets alive.

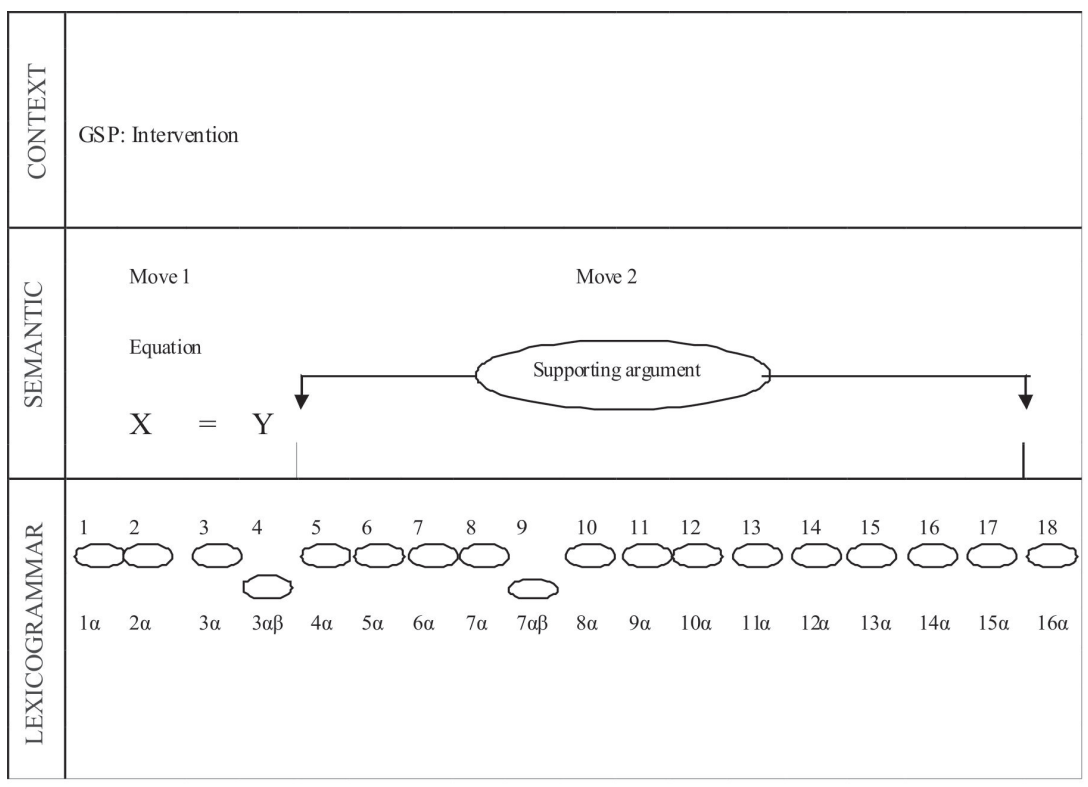

Figure 5. Multi-stratal Analysis: teacher 2

At the semantic level there are two moves which are realised into 18 clauses in lexicogrammar level. Clauses to clause relationships are both parataxis and hypotaxis. The types of mood are imperative and declarative. The clause complex in lexicogrammar shows that 
this teacher also uses critical abstraction in giving explanation. He models his explanation in a way that the student may follow his explanation well. Again, like the other teacher discussed before this teacher also tries to open the student' ZPD. Generally, as tenor network analysis reveals, this teacher is a type of teacher with weak framing and weak classification. However, as the above extract indicates that his classification becomes strong when he corrects the student's mistakes.

In pedagogy cycles (e.g Rothery and Stenglin, 1994; Martin, 1999) wave of framing and classification is crucial. It is a method that a teacher uses to explain a certain concept. At the opening move which is called deconstruction process a teacher tends to use weak framing and weak classification. At the phase a teacher wants to introduce the context to the students. He wants to open the student's mind on the field of the teaching. At the joint construction phase the framing and classification becomes stronger because the teacher wants the students stay in the context that they have just got from the deconstruction phase.

The extracts above demonstrate that the notion of guidance through interaction shapes each phase of pedagogy cycles. They also demonstrate that the linguistic choices are mobilised to enact movement through zone of proximal development during the scaffolding process.

\section{Conclusion}

In this paper I have tried to model context of pedagogic discourse. I use dalang training as special case because the issue of preserving culture. The SFL's metafucntions are used to describe this model since learning how to mean is multifunctional (Matthiessen, 2006: 38). The production of discourse is influenced by its context. Context is a semiotic system (see Halliday, 1978), but it is different form of semiotic system: language is a denotative semiotic system, whereas context is connotative semiotic system (Matthiessen, 2006:38). 
Classification and framing are also of great importance in pedagogic discourse. These will determine the production of discourse especially at the level of abstraction. As evidenced by the above analysis, context control meaning at the stratum of semantics, which is further control lexicogrammar at the lower stratum. The use of critical abstraction as a semantic concept is crucial. This strategy determines the linguistic choice as realised by clauses at the level of grammar.

\section{References}

Bernstein, B. (1971). Class, Code and Control: Theoritical Studies towards a Sociology of Language (Vol. 1). London: Routledge.

Bernstein, B. (1975). Class, Codes, and Control (Vol. 3). London: Routledge and Kegan Paul.

Bernstein, B. (1990). Classs, Codes and the Control: The Structuring of Pedagogic Discourse (Vol. 4). London: Routledge

Bernstein, B. (2000). Pedagogy, Symbolic Control, and Identity. Boston: Rowman and Littlefield Publishers, Inc.

Butt, D. G. (2000). Critical Abstractions and Rhetoric: the Latent Orger of Pedagogic Discourse. Mimeo: Dept of Linguistics, Macquarie University.

Butt, D.G. (2001). Firth, Halliday and the development of systemic functional theory. In S. Auroux \& E.F.K Koerner (Eds), History of language Sciences: An International Handbook on the Evolution of the Study of Language from the Beginning to Present (Vol.2, pp. 1806-1838). Berlin \& New York: Walter de Gruyter.

Butt, D.G. (2003). On establishing the similarities and differences between context. Mimeo: Dept of Linguistics, Macquarie University

Butt, D.G (2004) Parameters of Context: On Establshing the similarities and differences between social processes. Mimeo: Dept. of Linguistics, Macquarie University.

Caffarel, A., Martin,J.R \& Mattiessen, C.M.I.M. (Eds). (2004). Language Typology: A functional perspective. Amsterdam: John Benjamins Publishing Company. 
Cloran, C. (1999). Context for Learning. In F. Christie (Ed.), Pedagogy and the Shaping of Consciousness. London: Cassel.

Christie, F. (1999). The pedagogic device and the teaching of English. In F. Christie (Ed), Pedagogy and shaping of the consciousness. London: Cassell

Eggins, S. (2004). An introduction to systemic functional linguistics. New York: Continuum.

Eggins, S \& Martin, J.R (1997). Genres and Registers of Discourse. In T.A van Dijk (Ed.), Discourse as Structure and Process. (Vol. 1,pp. 230-256). London, Thousand Oaks \& New Delhi: Sage publications.

Groenendael, Victoria M.C. (1985). The Dalang behind the wayang. Dordreccht \& Cinnaminson: Foris Publication.

Halliday, M. A. K. (1978). Language as Social Semiotic. London: Edward Arnold.

Halliday, R. H. a. M. A. K. (1985). Language, Context, and Text: Aspects of Language in Social-Semiotic Perspective. Melbourne: Deakin University.

Halliday, M.A.K \& Martin, J.R. (1993). Writing Sciences: literacy and discursive power. Pittsburgh, PA: University of Pittsburgh Press.

Halliday, M.A.K \& Mattiessen, C.M.I.M. (1999). Construing Experience through Meaning: A Language-Based Approach to Cognition. London: Continuum.

Halliday, M.A.K \& Mattiessen, C.M.I.M. (2004). An Introduction to Functional Grammar (3 ${ }^{\text {rd }}$ ed.) London: Arnold.

Hasan, R. (1995). The conception of context in text. In P Fries. \& M Gregory (Eds), Discourse in society: systemic functional perspective. Oxford: Oxford University Press.

Hasan, R. (1999). Speaking with Reference to Context. In M. Ghadessy (Ed.), Tex and Context in Functional Linguistics (Vol. 169). Amsterdam: John Benjamins Publishing Company.

Hasan, R. (2005) Basil Benstein: an exceptional 1924-2000. In J.J Webster (Ed.), Language Society and Consciousness. London: Equinox.

Martin, J.R. (1992). English text: system and structure. Amsterdam \& Philadelphia: John Benjamins.

Martin, J. R. (1997). Analysing Genre: functional parameters. In F. Christie 
\& J.R Martin (Eds.), Genre and Institutions: Social processes in the workplace and school (pp. 1-39). London \& Washington: Cassell.

Martin, J. R. (1999). Mentoring Semogenesis: Genre-based Literacy. In C. Fraces (Ed.), Pedagogy and the Shaping of Consciousness. London: Cassel.

Martin, J.R \& Rose, D. (2007). Working with Discourse: Meaning beyond the clause ( $\left.2^{\text {nd }} e d\right)$. London: Continuum.

Mattiessen, C.M.I.M. (1993). Register in the round: diversity in a unified theory of register analysis. In M. Ghadessy (Ed.), Register Analysis: Theory and Practice (pp.221-292). London \& New York: Pinter Publishers.

Matthiessen, C.M.I.M. (2002). Combining clauses into clause complexes: a multiofaceted view. In J. Bybee \& M. Noonan (Eds.), Complex sentences in grammar and discourse: essays in honor of Sandra A. Thomson (pp. 237-322). Amsterdam: John Benjamins Publishing Company.

Rothery, J. and Stenglin, M. (1994). Writing a Book Review: A Unit of Work for Junior Secondary English (Write It Right Resources for Literacy and Learning). Sydney: Metropolitan East Disadvantages Schools Programme.

Teich, E. (1999). Systemic Functional Grammar in Natural Language Generation: Description and computational representation. London: Cassell.

Tharp, R.G \& Gallimore, R. (1988). Rousing minds to life. Cambridge: Cambridge University Press.

Van Ness, Edward C. (1980). Javanese wayang kulit: an introduction. Oxford: Oxford University Press

Veel, R. (1997). Learning how to mean -scientifically speaking: apprenticeship into scientific discourse in the secondary school. In F. Christie and J.R Martin, Genres and Institutions: Social Processes in the Workplace and School. London: Cassel, 161-95.

Ventola, E. (1987). The Structure of Social Interaction. London: Frances Pinter.

Wertsch, J. (1985). Vygotsky and the Social Formation of Mind. Cambridge, MA: Harvard University Press.

Recebido em: agosto de 2010 Aprovado em: outubro de 2010 tallapessy.albert@yahoo.com 